Performance Evaluation of Nitrogen for Fire Safety Application in Aircraft
A. Dinesh , C.M. Benson, P.G. Holborn, S. Sampath , Y. Xiong
PII:
S0951-8320(20)30545-7
DOI:
https://doi.org/10.1016/j.ress.2020.107044
Reference:
RESS 107044

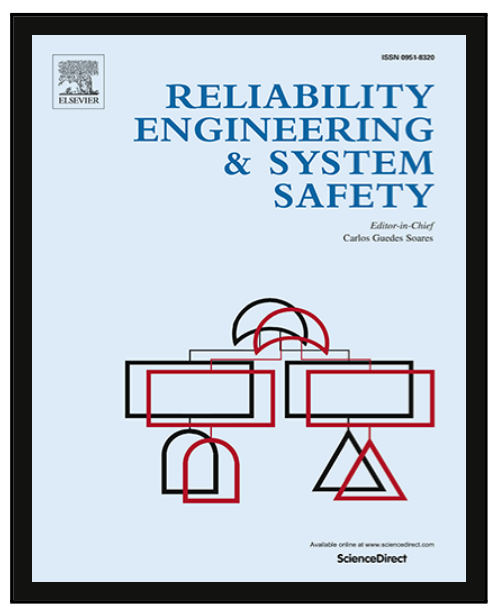

To appear in:

Reliability Engineering and System Safety

Received date:

2 September 2019

Revised date:

29 April 2020

Accepted date:

22 May 2020

Please cite this article as: A. Dinesh, C.M. Benson, P.G. Holborn, S. Sampath, Y. Xiong , Performance Evaluation of Nitrogen for Fire Safety Application in Aircraft, Reliability Engineering and System Safety (2020), doi: https://doi.org/10.1016/j.ress.2020.107044

This is a PDF file of an article that has undergone enhancements after acceptance, such as the addition of a cover page and metadata, and formatting for readability, but it is not yet the definitive version of record. This version will undergo additional copyediting, typesetting and review before it is published in its final form, but we are providing this version to give early visibility of the article. Please note that, during the production process, errors may be discovered which could affect the content, and all legal disclaimers that apply to the journal pertain.

(C) 2020 Published by Elsevier Ltd. 


\section{Highlights}

- The title of the topic was changed to: Performance Evaluation of Nitrogen for Fire Safety Application in Aircraft

- Simulation of cup-burner test through CFD

- Reconsider the pool-fire case in CFD

- Meaningful discussion and conclusion regarding the observations made during this study.

- Additional references were included from RESS journal 


\title{
Performance Evaluation of Nitrogen for Fire Safety Application in Aircraft
}

\author{
Dinesh, $\mathrm{A}^{\mathrm{a}}$, Benson, $\mathrm{CM}^{\mathrm{b}}$, Holborn, $\mathrm{PG}^{\mathrm{b}}$, Sampath, $\mathrm{S}^{\mathrm{a}}$ and Xiong, $\mathrm{Y}^{\mathrm{a}}$ \\ ${ }^{a}$ Centre for Propulsion, School of Aerospace, Manufacturing and Transport, Cranfield \\ University, Befordshire, MK43 0AL, UK \\ ${ }^{\mathrm{b}}$ Explosion \& Fire Research Group, London South Bank University, London, SE1 0AA, UK
}

\begin{abstract}
Fire suppression is an important safety certification requirement for aircraft as it is for all safety critical systems. Risk analyses are required at the design and certification stages to determine the probabilities and means of mitigating such risks. [18] shows an approach for spacecraft, [19] for passenger ships and [30] for reactors. An important analysis tool for aircraft is the Zonal Analysis process [31]. Such analyses include investigation of means of fire suppression for which the use of Halon 1301 was a popular choice. The production of Halon and several halocarbons were banned under the Montreal Protocol in 1994, which necessitates an investigation for use of environmental-friendly agents for this application. The primary objective of this paper is to determine the "design concentration" required for fire suppression. Computational Fluid Dynamics (CFD), in combination with experimental verification is described in this paper. The air flow rate in the cup-burner model was varied between $10 \mathrm{~L} / \mathrm{min}$ and $40 \mathrm{~L} / \mathrm{min}$ for a low-speed numerical model and was validated against the BS ISO 14520 cup burner test [1] to determine the extinguishing concentration of nitrogen. The study revealed that the design concentration of nitrogen was $34 \%$ (14\% oxygen concentration). Further investigation suggested that at low air flow rates (10L/min and $20 \mathrm{~L} / \mathrm{min}$ case), distortions produced in the flow led to erroneous measurement of oxygen concentration in experiments. The fire suppression model was extended to an nheptane pool fire in a large enclosure. The recorded design concentration was approximately $39 \%$ additional nitrogen corresponding to $13 \%$ oxygen concentration by volume. It was observed that the weight of nitrogen required increased by 7.5 times compared to Halon 1301 use for this model. Future work can be explored in aircraft cargo and engine bay fire safety systems through Minimum Performance Standard (MPS) testing and simulations with nitrogen as the agent. Such work will feed directly into system safety assessments during the early design stages, where analyses must precede testing.
\end{abstract}

April 2020

1. Nomenclature

\begin{tabular}{|c|l|}
\hline Abbreviation & \multicolumn{1}{|c|}{ Description } \\
\hline$D^{*}$ & Characteristic fire diameter $(\mathrm{m})$ \\
\hline$\dot{Q}$ & Heat release rate $(\mathrm{HRR})(\mathrm{kW})$ \\
\hline$T_{\propto}$ & Ambient temperature $(\mathrm{K})$ \\
\hline$c_{p}$ & Specific heat capacity of air $(\mathrm{J} / \mathrm{kg}-\mathrm{K})$ \\
\hline$\rho_{\propto}$ & Density of air $\left(\mathrm{kg} / \mathrm{m}^{3}\right)$ \\
\hline$C_{E}$ & Agent concentration $\%(\mathrm{volume})$ for flame extinction \\
\hline$g$ & Acceleration due to gravity $\left(\mathrm{m} / \mathrm{s}^{2}\right)$ \\
\hline $\mathrm{CFC}$ & Chlorofluorocarbon \\
\hline$C_{O}$ & Oxygen concentration $\%($ volume $)$ in the air/agent mixture at \\
\hline
\end{tabular}

${ }^{1}$ Design concentration is the volumetric concentration of the agent to achieve successful fire suppression in an enclosure 


\begin{tabular}{|c|l|}
\hline & flameout \\
\hline$C_{S}$ & Oxygen concentration \% (volume) of the supply air. \\
\hline DES & Detached Eddy Simulation \\
\hline DNS & Direct Numerical Solution \\
\hline FAA & Federal Aviation Administration \\
\hline FDS & Fire Dynamics Simulator \\
\hline GWP & Global Warming Potential \\
\hline HRR & Heat Release Rate \\
\hline LES & Large-Eddy Simulation \\
\hline MPS & Minimum Performance Standard \\
\hline ODP & Ozone Depletion Potential \\
\hline$S$ & Specific vapour volume of the agent $\left(\mathrm{m}^{3} / \mathrm{kg}\right)$ \\
\hline$V$ & Volume of enclosure $\left(\mathrm{m}^{3}\right)$ \\
\hline$W$ & Weight of the agent $(\mathrm{kg})$ \\
\hline
\end{tabular}

\section{Introduction}

Commercial aircrafts undergo rigorous certification processes as safety is a primary concern. Fire on-board can lead to a catastrophic disaster as there is no means of evacuation when the aircraft is airborne. Some of the cases like the 1976 incident of Indian Airlines 171 [2] and South African Airways 295 in 1987, [3] where all passengers on board were lost, demonstrated why fire safety is critical. Risk analyses are therefore required at the design and certification stages to determine the probabilities and means of mitigating such risks. Lessons can be learnt from other safety-critical Industries, such as [18] which shows an approach for spacecraft, [30] for reactors and [19] for passenger ships. An important analysis tool for aircraft is the Zonal Analysis process [31]. [18] also refers to the fire triangle which shows different means of controlling fires (See Figure 1). Such analyses include investigation of the means of fire suppression. Fires can be controlled and suppressed when the fuel subjected to combustion is withdrawn but is not possible in case of an aircraft. Fire suppression can be achieved by introduction of a suppression agent which reduces the overall oxygen

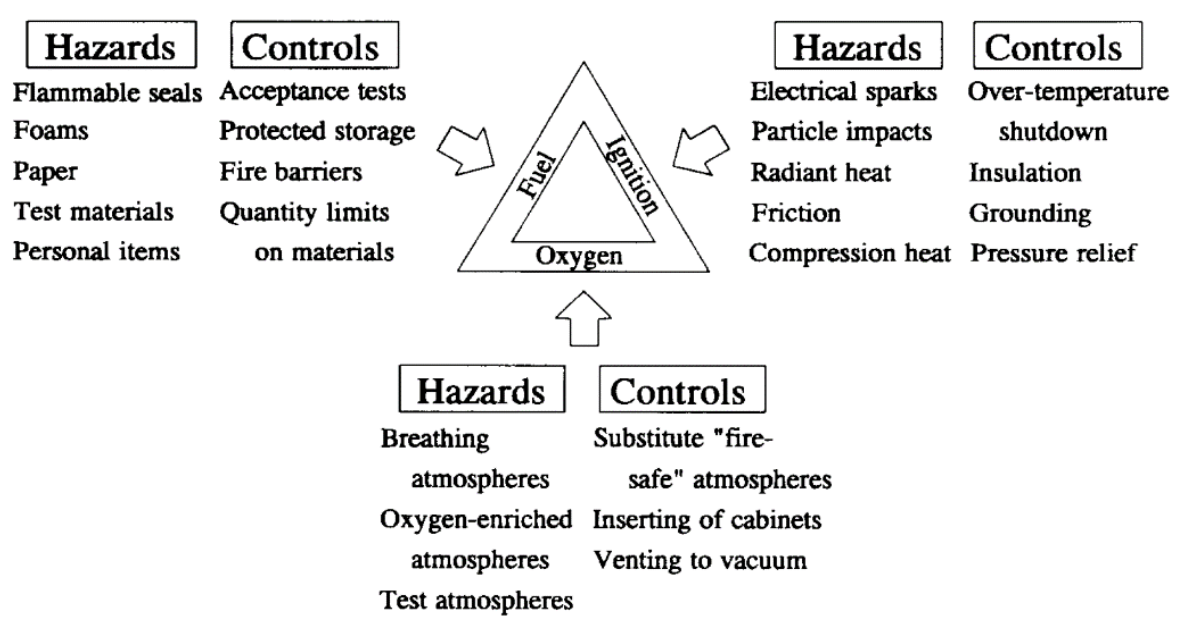

Figure 1: Fire Triangle [18] 
concentration, causing the flame to starve, destabilise and eventually to die.

\subsection{Why Nitrogen?}

Halons, or halogenoalkanes, are extremely effective fire suppression agents. Halon 1301 (Bromotrifluoromethane), has been used extensively to fight fires in commercial aviation for some 60 years. However, the production of Halon was ceased in January 1994 following an international agreement, named the Montreal Protocol (MOP). This was because Halon agents are not environmental-friendly [4]. Although, many current generation aircraft still use Halon agents, the Halon commission end-date is set to 2040 for fixed fire suppression systems, [5] which calls for replacement of existing Halon systems. Several efforts are underway by different airframe manufacturers, fire suppression agent manufacturers and research organisations to find a way forward to this problem. The work described is being undertaken as part of the Clean Sky 2- Platform 2 project titled- EFFICIENT, which aims at developing new fire suppression technology for cargo compartments of next generation aircraft.

The FAA has assembled the International Halon Replacement Working Group which develops the concepts and factors to qualify replacement agents for aircrafts. There are several aspects to be considered for Halon replacement agents before qualifying as a worthy replacement under 14 CFR 25.795 [6]. 14 CFR 25.851 [7], 14 CFR 25.857 [8], and 14 CFR 25.1309 [9]. This includes suitability for Class A and B fires, Oxygen Depletion Potential (ODP), Global Warming Potential (GWP), low toxicity, should not impose additional departure delay following a false discharge, minimal post discharge clean-up, should not be subject to additional transport restrictions (relative to current Halon 1301 systems) etc. A detailed report is available for factors and attributes of agents on the 'Options to Use of Halons for Aircraft Fire Suppression Systems' [4]. Additionally, the agent should be subjected to testing, following the guidelines of the Minimum Performance Standards (MPS) for cargo fire suppression. A series of four experimental tests need to be conducted to prove the fire suppression capabilities in bulk-load fire, containerised-load fire, surface burning fire and aerosol can explosion test scenarios as specified in the FAA MPS document [10].

ODP and GWP are two vital properties for preliminary consideration of replacement agents. ODP is the potential to destroy a unit mass of ozone gas per unit mass of agent relative to CFC-11. It is recommended that the ODP should be less than 0.02 for new agents replacing Halon agents [11]. GWP is the change in radiative forcing ${ }^{2}$ as a result of emission of 1 kilogram of the agent relative to the radiative forcing as a result of emission of 1 kilogram of $\mathrm{CO}_{2}$. GWP influences the atmospheric lifetime of the agent. The gas is assumed to decay exponentially however the gas concentration will never be absolute zero after being released into the atmosphere. This would mean that the agent circulates within the atmosphere for long periods of time causing further ozone depletion and global warming during its decay. It is recommended that modern fire suppression agents exhibit a GWP value of less than 150 [12].

Table 1: Agent ODP, GWP and Atmospheric lifetime [11] [12]

\begin{tabular}{|c|c|c|c|}
\hline Agent & ODP & GWP (After 100 & Atmospheric \\
\hline
\end{tabular}




\begin{tabular}{|c|c|c|c|}
\hline & & years cycle) & Lifetime (Years) \\
\hline CFC-11 & 1.0 & 4750 & 45 \\
\hline Halon 1301 & 16.0 & 7140 & $65.5-68.6$ \\
\hline Halon 1211 & 5.1 & 1890 & $18.5-20.1$ \\
\hline Halon 1202 & 1.3 & 1640 & $23.4-25.5$ \\
\hline HFC 125 & 0.005 & 2800 & 129 \\
\hline Nitrogen & $<0.001$ & $<1$ & 0 \\
\hline
\end{tabular}

Table 2: Nitrogen compliance matrix

\begin{tabular}{|c|c|c|}
\hline Requirement & Compliance & Details \\
\hline Environmental & Compliant & $\begin{array}{c}\text { About } 78 \% \text { of the atmosphere is nitrogen; } \\
\text { no environmental issues }\end{array}$ \\
\hline Desired Characteristics & Compliant & $\begin{array}{l}\text { Effective; near-zero OPD and GWP; clean } \\
\text { agent and no residue }\end{array}$ \\
\hline Performance & $\begin{array}{l}\text { Likely to be } \\
\text { compliant }\end{array}$ & $\begin{array}{l}\text { Tests have shown that nitrogen-water mist } \\
\text { agent can pass all tests in FAA MPS }\end{array}$ \\
\hline Health and Safety & Compliant & $\begin{array}{l}\text { No known health issues; safe to use; no } \\
\text { pyrolytic residue products; agent reduces } \\
\text { oxygen concentration }\end{array}$ \\
\hline Temperature & Compliant & $\begin{array}{l}\text { Nitrogen fulfils the FAA MPS } \\
\text { temperature requirements }\end{array}$ \\
\hline Integration and Operations & Compliant & $\begin{array}{l}\text { Nitrogen is clean and non-corrosive; } \\
\text { pressure reducing valves can rectify over- } \\
\text { pressure conditions }\end{array}$ \\
\hline
\end{tabular}

Common halocarbon agents are highly effective and meet the FAA MPS specified temperature requirements. They are easy to integrate and show acceptable levels of toxicity. It is highly desirable to find alternatives with performance characteristics similar to halocarbons. Many agents, such as carbon-dioxide, water mist and inergen (Blend of nitrogen, carbon-dioxide and argon) [4] are being investigated for operating compliance (Table 2). Several alternative agents are listed in the 'Chemical Options Report' developed by FAA [13]. Following the guidelines provided, nitrogen agent was chosen by the consortium for study in this project, due to its desirable properties and compliance in operation.

\subsection{Role of CFD}

CFD is extremely helpful in solving fluid problems by reducing the effort and cost associated with experiments. The solutions are fairly accurate and are a good representation of the physical flow problem, if modelled correctly. It helps the user visualise flow patterns which helps to indicate critical operating variables and provides guidance for the experimental setup. FDS [14] is the numeric computational tool used in this paper.

A study conducted by McGrattan et al., [15] revealed that the definition of boundary conditions at nozzles alters the extinction criteria significantly in FDS. The injection of the 
agent must be modelled by specifying velocities about all angles in a sphere around the nozzle, to improve the accuracy of the model. A CFD investigation on temperature and fuel particle distribution has been carried out by Defence Research and Development, Canada [16] in OpenFOAM, ANSYS CFX and FDS. OpenFOAM uses DES and was unable to handle fire suppression modelling due to lack of a database to solve the governing equations. The demonstration in CFX required 9.5 hours to advance the solution time to 20 seconds which used a relatively coarse grid ( $25 \times 25 \times 25$ cells) using the first order upwind scheme. The study conducted using FDS required 5 minutes and 26 seconds to complete the same simulation. Further investigation revealed that this is because CFX utilises implicit integration, maintaining close accuracy to the physical flow problem. FDS uses a less-stable explicit integration and requires calibration of the solver prior to obtaining the solution based on the problem. A study conducted by Adiga et al., [17] shows that FDS is also infeasible for high Mach number flow due to the large number of Lagrangian particles and hence, increased processing time.

The fire suppression mechanism would include identification of critical locations of fire risk, assessment of frequency of occurrence, fire growth time, estimation of detection and corresponding agent delivery time and how the system deals with the event upon completing the suppression process [18]. This paper is focused on fire detection and corresponding agent delivery time for specified heat release rate of fire. The heat release rate calculation influences the fire design principle incorporated in simulations. The representation of design fire is carried out in modelling four phases of fire - (1) linear in time in the incipient stage (2) time-squared in growth stage (3) steady with time in the full fire development phase and (4) exponential growth in decay phase [19]. In FDS, the maximum heat release is assumed to be attained when a predetermined portion of the fire load has been consumed during the decay period. The results obtained from CFD will have an influence on the design of the agent delivery system and the amount of nitrogen required to suppress fire in an enclosure. Standard chemistry formulations suggest that the combustion process ceases at an oxygen concentration level of $16 \%$. However, this number is quite high for practical applications. The extinguishing concentration depends on various factors such as type and properties of agent used, air flow rate inside the enclosure, average heat release rate during combustion, the size of enclosure etc.

\section{Methodology}

The study described in this paper used CFD to estimate the performance of nitrogen in fire suppression for a propane cup-burner test. Propane is one of the standard fuels used in BS ISO cup-burner tests [1]. The modelling of the fire suppression characteristics is critical in the evaluation of the design concentration of the agent. The results were then validated against the cup-burner experiment to establish the design concentration. The suppression model formulated is further extended to an n-heptane pool fire to represent the surfaceburning scenario specified in MPS [10].

\subsection{Cup-burner Experiment}

The cup burner test (BS ISO 14520 Annex B) is a recognised method to evaluate the extinguishing concentration of an agent. The apparatus used for this work was designed and built to match the specification in BS ISO 14520 (2006) [1]. The structure of the rig was 3-D printed in solid ABS polymer. The apparatus consists of inlets for nitrogen (99.9\% purity via 
a rotameter) and air (fed in through a drying agent) that enter a chamber for mixing below the diffuser. The temperature is monitored using RS thermometer and a calibrated Servomex OA 150 paramagnetic oxygen analyser is used to directly measure the oxygen concentration. The ISO 14520-defined glass cup has the following dimensions - 235mm height, $12 \mathrm{~mm}$ tube outer

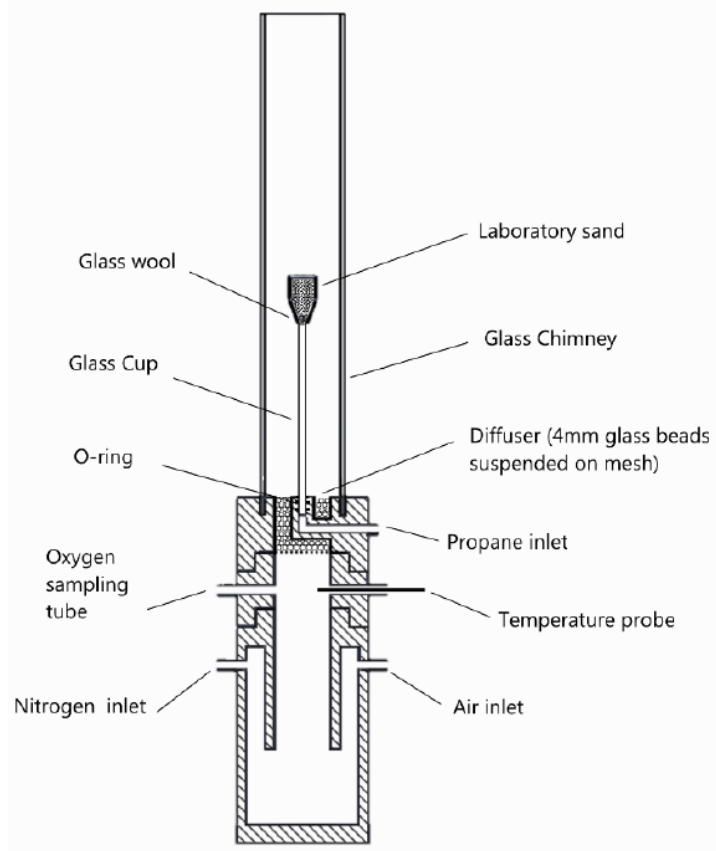

Figure 2: Cup burner setup

diameter with a cup section of $28-32$ outer diameter and $50 \mathrm{~mm}$ height with a $45^{\circ}$ chamfer.

It was inserted into the outlet and sealed using nitrile rubber o-rings. The cup was filled with laboratory sand for fuel diffusion. Propane gas entered the chamber for combustion and had an adjustable flow rate. The cup was placed inside a glass chimney of $535 \mathrm{~mm}$ height and $85 \mathrm{~mm}$ inner diameter. The procedure carried out to conduct the experiment followed the BS ISO 14520 (Annex B) guidelines. The air flow rate was verified for $10 \mathrm{~L} / \mathrm{min}$ and $40 \mathrm{~L} / \mathrm{min}$ to check the results against Ural's publication [20] and the CFD simulation. The height of the flame was adjusted to $80 \mathrm{~mm}$ which corresponds to a propane gas flow rate of $0.165 \mathrm{~L} / \mathrm{s}$. The fuel was ignited and allowed to burn for a period of 60 seconds to achieve stability. The agent (nitrogen) flow rate was increased gradually with an increment of no more than $3 \%$ of the previous value until the flame was extinguished. Adjustments to the nitrogen flow rate were followed by a brief waiting period of up to 10 seconds to allow the new proportions of the agent and air in the manifold to reach the cup position.

\subsection{Simulation Setup}

FDS is an open source LES code for low-speed flows developed by United States National Institute for Standards and Technology (NIST). FDS lays emphasis on heat transport from fires and makes it a prime choice for the type of studies conducted in this paper. LES captures flow particles with an accuracy dependant on the specified grid size and smaller scales are modelled numerically. Although a high-density mesh, with fine grid sizes, may be used to 
capture all scales through DNS option in FDS, it is extremely expensive and hence, deemed to be impractical [14].

\subsubsection{Cup-burner Simulation}

A 2-D cup-burner simulation was carried out using the specifications of the experiment. Only one half of the cylinder was simulated (symmetric) to reduce the convergence time required for the solution. An input file for FDS was generated with concentric inlets. The inner inlet (propane fuel) had a radius of $15 \mathrm{~mm}$ and the outer inlet (fuel-nitrogen mixture) had a radius of $42.5 \mathrm{~mm}$. The height of the setup in the z-direction was $535 \mathrm{~mm}$ with an elevation of $235 \mathrm{~mm}$ for propane fuel inlet. The mesh was distributed with a size of $1 \mathrm{~mm} \times 1 \mathrm{~mm}$ per cell with a total of 22377 cells.

The inner cylinder is a propane fuel inlet with a constant flow rate of $0.165 \mathrm{~L} / \mathrm{min}$. The outer cylinder carries air which is varied between $10 \mathrm{~L} / \mathrm{min}$ and $40 \mathrm{~L} / \mathrm{min}$ (four simulation cases) with a step change of $10 \mathrm{~L} / \mathrm{min}$ between each simulation. Air was introduced with a

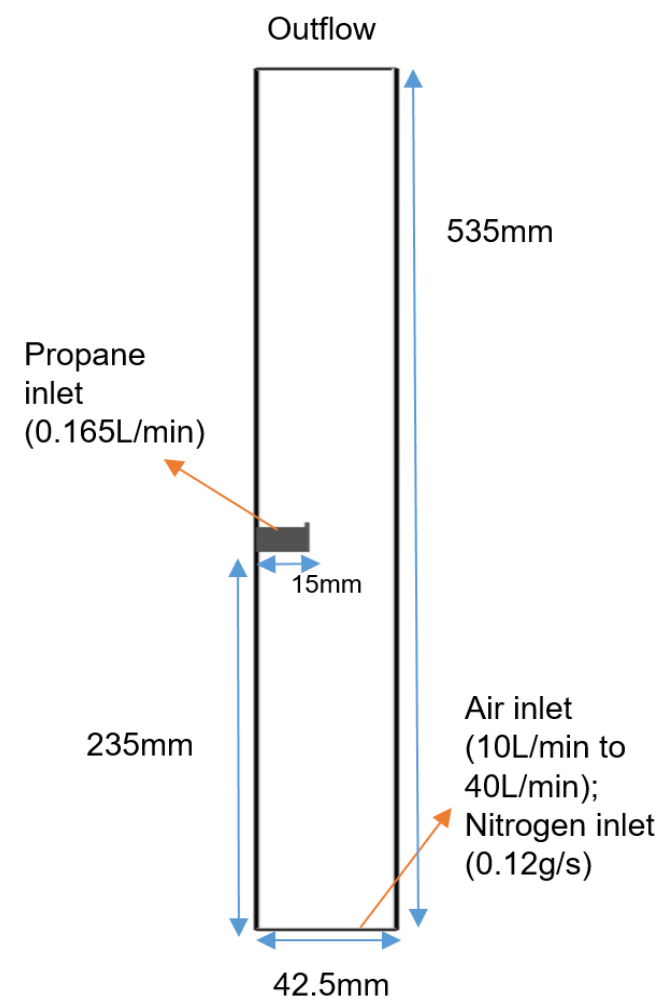

Figure 3: Cup burner CFD model

temperature and pressure of $300 \mathrm{~K}$ and 1.01 bar respectively.

The assumption made was that the flame was stabilized at the start of simulation. Nitrogen agent was introduced to the air inlet tube at a rate of $0.12 \mathrm{~g} / \mathrm{s}$ to study the flame extinction criteria. The temperature and pressure of the agent were $288 \mathrm{~K}$ and 1.5 bar respectively. The total simulation time was set to 20 seconds for each case. A temperature-time loop checked the consistency of temperature continuity with time. The time step was determined by the Courant-Friedrich-Lewy (CFL) condition.

$$
C F L=\Delta t \frac{|u|}{\Delta}<1
$$


Where $\Delta t$ is the time step, $u$ is the velocity magnitude of the fluid and $\Delta$ is the length interval. The calculated time step for the simulation was $0.006 \mathrm{~s}$ to maintain the solution stability. The solution convergence for each case completed at approximately 54600 iterations with a runtime of 2 hours 20 minutes using 4 processors on a parallel platform.

Nitrogen agent reduces the fuel pyrolysis rate by reducing the oxygen available for combustion. This effect eventually leads to suppression of fire or flame extinction in this case. The exhaustion of oxygen within the enclosure is a challenging environment to simulate as the relevant physical mechanisms occur at sub-grid scales. The simulation of suppression and reignition within local fuel-rich pockets are based on average cell temperature and oxygen concentration. The detailed thermophysical gas species transport is not invoked in these calculations. The Simple Very Large Eddy Simulation (SVLES) model, a simplified extinction model in FDS, utilises critical flame temperature (CFT) based on oxygen index concept. The oxygen index is the volume fraction of oxygen in the oxidizer stream when extinguishment occurs [21]. The limiting oxygen concentration, $T_{O I}$, dictates the adiabatic flame temperature of the fuel-air mixture taken at the CFT values calculated using -

$$
T_{O I}=T_{0}+X_{O I} \frac{\Delta H_{c} / r}{n c_{p}}
$$

Where $T_{0}$ is the initial temperature of fuel-air mixture $(\mathrm{K}), X_{O I}$ is the limiting oxygen volume fraction, $\Delta H_{c} / r$ is the heat of combustion per mole of oxygen consumed $(\mathrm{kJ} / \mathrm{mol}), c_{p}$ is the average heat capacity of products of combustion $(\mathrm{kg} / \mathrm{mol} . \mathrm{K})$ and $n$ is the number of moles of products of combustion per mole of fuel-air mixture.

The code calculates the CFT based on the available oxygen mass fraction for combustion. The extinguishing concentration was determined based on the formulation provided above in the code. The percentage of nitrogen agent was hence, computed based on the oxygen index value. The specified CFT value for propane fuel is $1427^{\circ} \mathrm{C}$ assuming an oxygen index of 0.127 [21]. This concept can also be used for auto-ignition when studying fire scenarios is aircraft cargo and can predict the level of damage to materials inside the enclosure.

\subsubsection{Heptane Pool Fire Simulation}

Since cup-burner tests are small cases and are not applicable for real-life scenarios, the fire suppression model was extended to study a pool fire case (3D) in an enclosure to understand the design concentration requirements for suppression in large fire scenarios. Boundary conditions for initialisation are specified at the solid surfaces of the geometry. These surfaces determine the material flammability characteristics and thermal conditions at the surface. Numerical empirical co-relations are used at the solid boundary. Aluminium was chosen as the material specified at the solid boundary. Standard material and heat transfer properties for Aluminium are available on the software database. Navier-Stokes equations calibrated for low-Mach number were used for hydrodynamic modelling. A second-order space and time explicit corrector-predictor method was used for space and time marching.

Fire pool setup in the model is of vital importance as sources indicate that using a rectangular surface fire pool is the appropriate method to estimate the extinguishing concentration of an agent in FDS [22][23]. A study by Kim and Ryou [24] suggests the use of appropriate heat release rates for various fuels which translate to the peak temperature sensed by the simulator. Many of the variables in the governing equations and empirical formulations are 
dependent on HRR. The fuel used for study in this case was n-heptane. A study conducted on forensic analysis of liquid fuel fires [25] estimated the heat release rate (HRR) of n-heptane pan fire revealed that the HRR per unit area (HRRPUA) of n-heptane corresponds to approximately $800 \mathrm{~kW} / \mathrm{m}^{2}$ for stoichiometric combustion. This case uses a pool fire setup for $\mathrm{n}$-heptane burning on a surface with a fire area of $0.5625 \mathrm{~m}^{2}(0.75 \mathrm{~m} \times 0.75 \mathrm{~m})$ resulting in a HRR of $450 \mathrm{~kW}$.

For consistent results in FDS, the software requires the user to use structured Cartesian grids. The governing equations are solved through approximations on the rectilinear grids. Meshes are divided into a space domain which are induced by the flow in the simulation. The resolution is formulated by characteristic length scales which can be chosen using Poisson's equation based on Fast Fourier Transform (FTT). The characteristic fire diameter can be calculated using

$$
D^{*}=\left(\frac{\dot{Q}}{\rho_{\propto} c_{p} T_{\propto} \sqrt{g}}\right)^{2 / 5}
$$

From the above equation 3 , the characteristic fire diameter is $0.7 \mathrm{~m}$. The general recommendation for mesh resolution is defined by $\mathrm{D}^{*} / \mathrm{dx}$. The term $\mathrm{dx}$ represents the length of the cell in the model, where $4<\mathrm{D}^{*} / \mathrm{dx}<16$ will give good resolution. The range of $\mathrm{dx}$ can be between $0.175 \mathrm{~m}$ and $0.04 \mathrm{~m}$. A value of $0.05 \mathrm{~m}$ for $\mathrm{dx}$ was assigned in the simulation which provided a grid independent solution. Hence, the number of cells can be obtained based on the dimensions assigned for the geometry. The simulation was carried out with a cuboid geometry of $2.5 \mathrm{~m} \times 2.5 \mathrm{~m} \times 2 \mathrm{~m}$. The total mesh count is 100,000 cells $(50 \times 50 \times 40$ cells $)$. A small vent was allocated with an area of $0.2 \mathrm{~m} \times 0.2 \mathrm{~m}$ on the right-hand wall of the model to allow venting of exhaust gases and to maintain pressure equilibrium. The placement of this vent in the model had an impact on the location of the maximum temperatures achieved in the model. However, it did not alter the suppression time or concentration of the agent in the chamber. The fire area allocated was a $0.75 \mathrm{~m} \times 0.75 \mathrm{~m}$ surface placed $0.3 \mathrm{~m}$ above the floor level. The aim of choosing this area for the fire surface is to replicate the surface-burning test in aircraft cargo specified by FAA [10]. The fire area was located at the centre of the test chamber. Like the cup-burner test, the SVLES model was used to compute the extinguishing criteria for this simulation.

The nozzle was configured to inject nitrogen at a rate of $0.4 \mathrm{~kg} / \mathrm{s}$ with a spray angle of $60^{\circ}$. Although this injection speed will be much higher in real scenarios, the FDS code is optimised for low-speed flows. Nitrogen was injected when any one of the thermocouples sensed a temperature of $550^{\circ} \mathrm{C}$ after simulation commences to allow flame stability in the pool fire. The total simulation time was set to 30 seconds upon commencement of nitrogen introduction into the chamber. The total CPU run-time for this simulation was 17 hours and 50 minutes with 16 processors.

The reference temperature and pressure of the model were $300 \mathrm{~K}$ and 1 bar respectively. The simulation was carried out with nitrogen agent temperature and pressure at $288 \mathrm{~K}$ and 2 bar respectively. A temperature-time loop checked the consistency of temperature continuity with time. The time step determined by the Courant-Friedrich-Lewy (CFL) condition was $0.008 \mathrm{~s}$. 


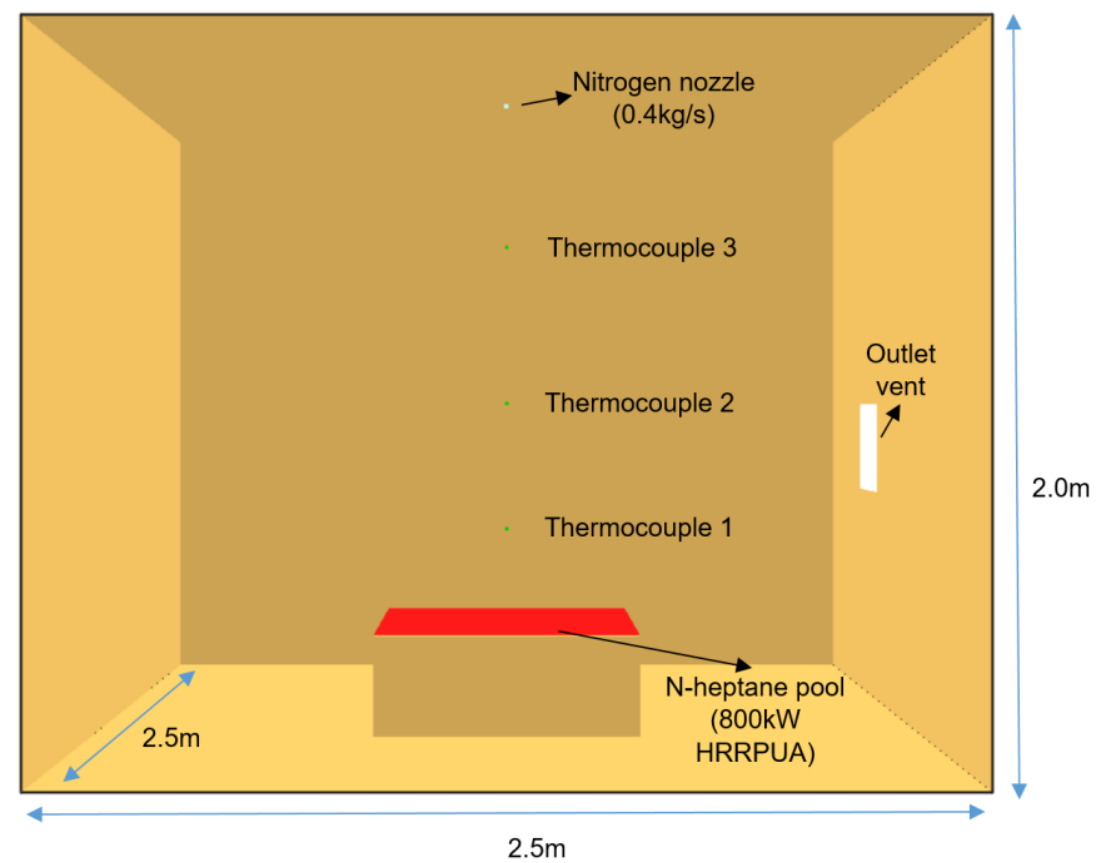

The turbulence Prandtl number was set to 0.7 and Schmidt number to 0.5. Van Driest damping was incorporated in the Smagorinsky's LES model [26] for eddy viscosity associated with the initial cell. The damping function was used to represent the no slip condition at the wall boundaries.

Initial conditions for the model were provided by entering the volume fractions of the gases in the test chamber -0.78 nitrogen, 0.21 oxygen and 0.01 argon. Three thermocouple sensors were placed at $0.6 \mathrm{~m}, 1.0 \mathrm{~m}$ and $1.5 \mathrm{~m}$ in the vertical (z-plane) direction directly above the fire zone. The operating density of air was $1.2 \mathrm{~kg} / \mathrm{m}^{3}$. Acceleration due to gravity specified was $9.81 \mathrm{~m} / \mathrm{s}^{2}$.

Figure 4: Pool fire model in FDS

\section{Results and Discussion}

\subsection{Cup-burner Experiment Results}

The experiment was performed as a means of verifying the work carried out by Ural [20] to determine the extinguishing concentration of nitrogen in a standard cup-burner test mentioned throughout the paper. Five different runs were conducted at $40 \mathrm{~L} / \mathrm{min}$ to establish the nitrogen concentration required for flame extinction. A sixth run for $10 \mathrm{~L} / \mathrm{min}$ was also recorded.

Table 3: Experimental measurement (oxygen concentration) and calculated nitrogen concentration

\begin{tabular}{|c|c|c|}
\hline Run No. & $\begin{array}{c}\text { Oxygen \% (volume) } \\
\text { measured at flame } \\
\text { extinction }\end{array}$ & $\begin{array}{c}\text { Additional Nitrogen \% } \\
\text { (volume) calculated at } \\
\text { flame extinction }\end{array}$ \\
\hline 1 & 13.9 & 33.7 \\
\hline 2 & 13.9 & 33.7 \\
\hline 3 & 13.8 & 34.1 \\
\hline
\end{tabular}




\begin{tabular}{|c|c|c|}
\hline 4 & 13.9 & 33.7 \\
\hline 5 & 13.7 & 34.6 \\
\hline $6(10 \mathrm{~L} / \mathrm{min})$ & 12.7 & 38.5 \\
\hline
\end{tabular}

The oxygen concentration was measured, and the additional nitrogen concentration was calculated using -

$$
C_{E}=100\left(1-\frac{C_{o}}{C_{S}}\right)
$$

Equation 4
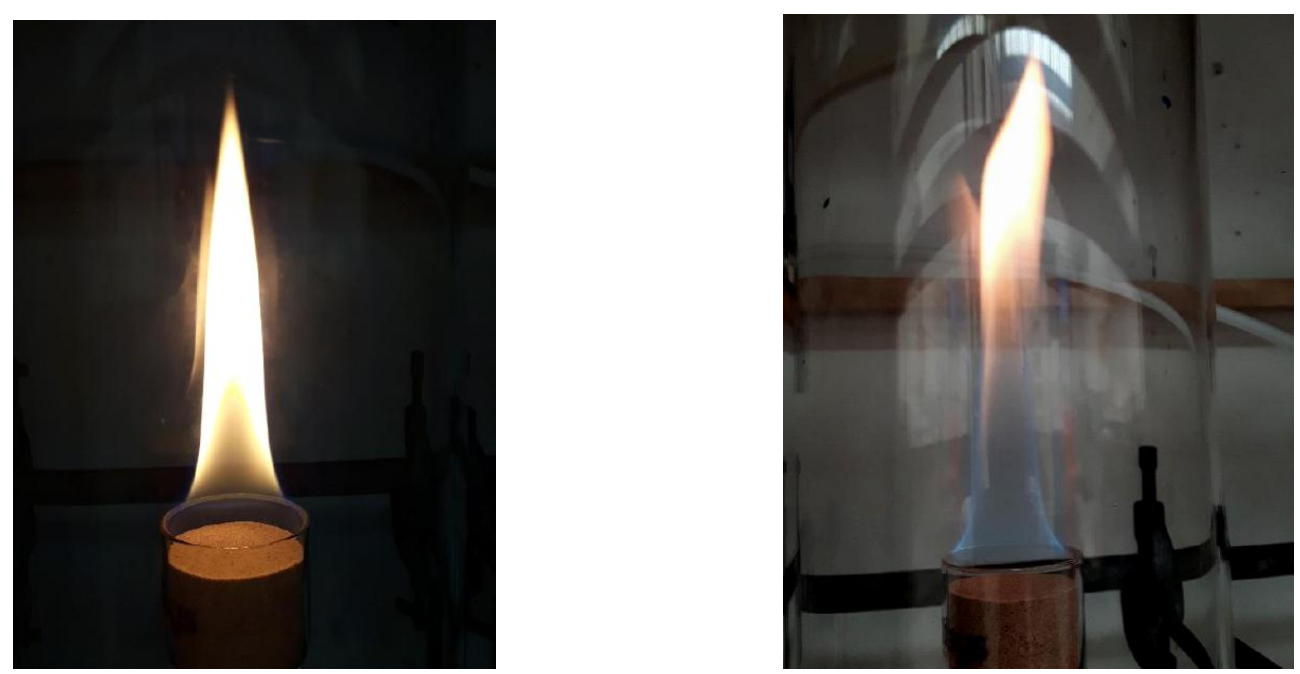

Figure 5: (Left) Stable diffusion flame in the cup-burner experiment; (Right) Flame destabilising due to reduced oxygen concentration

\subsection{Simulation}

\subsubsection{Cup-burner simulation}

The solution from FDS was post-processed using Smokeview [14] available within the FDS package. Figure 5 shows the variation of temperature during the course of the simulation for 40L/min case.

At $\mathrm{t}=0 \mathrm{~s}$, the flame is stabilized with a constant flow of $0.165 \mathrm{~L} / \mathrm{min}$ propane being supplied. Nitrogen was then supplied at a constant rate of $0.12 \mathrm{~g} / \mathrm{s}$ in addition to the $40 \mathrm{~L} / \mathrm{min}$ air. The air and nitrogen agent was mixed in the channel before reaching the propane inlet obstruction. The maximum flame temperature observed in the slice was $1235^{\circ} \mathrm{C}$ with an average slice temperature of $390^{\circ} \mathrm{C}$.

At $t=5 \mathrm{~s}$, the effect of introduction of nitrogen can be observed and the average slice temperature decreased to $365^{\circ} \mathrm{C}$. The oxygen concentration fall affected the combustion of propane and the length of the flame reduced.

At $\mathrm{t}=10 \mathrm{~s}$, the reduction in oxygen concentration is more pronounced where the flame length is small. The combustion of propane continues, however, due to oxygen starvation the 
combustion process is incomplete resulting in lower flame temperature and a lower average slice temperature.

At $\mathrm{t}=15 \mathrm{~s}$, the flame was almost extinct with nitrogen concentration rising above $30 \%$. The combustion process was not sustained based on the oxygen index calculated by the code.

At approximately $\mathrm{t}=16.2 \mathrm{~s}$, the flame was extinct, and the suppression was completed. The observed nitrogen concentration at this point was $33.6 \%$ with a corresponding oxygen concentration of $14 \%$ for $40 \mathrm{~L} / \mathrm{min}$ airflow. Although, propane is subject to combustion, the oxygen index does not allow the fuel to burn causing no heat release. The simulation resumes until $\mathrm{t}=20 \mathrm{~s}$ where nitrogen is injected, however, the concentration is noted at the point the

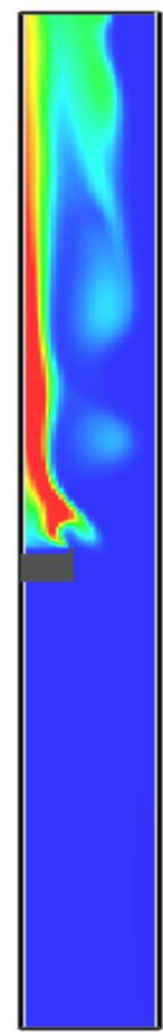

Os

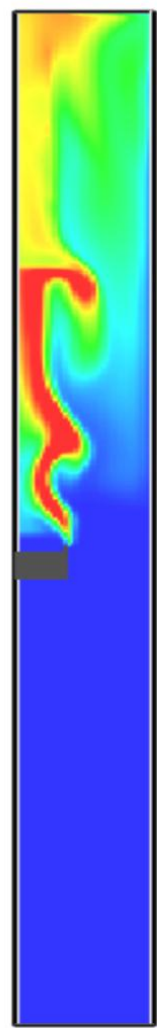

5s

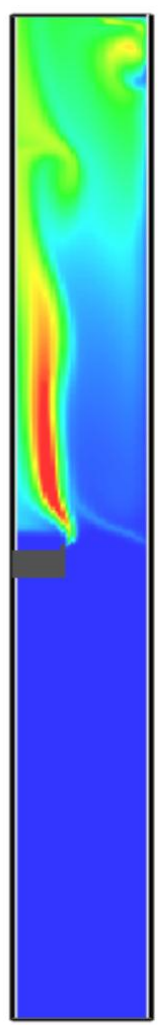

10s

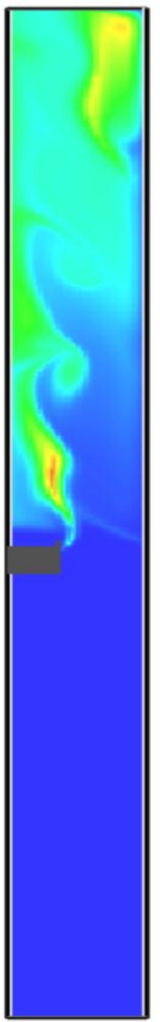

$15 s$

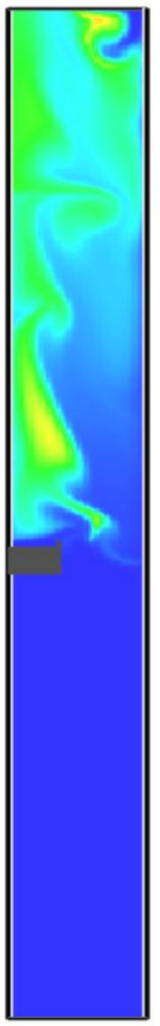

$16.5 \mathrm{~s}$

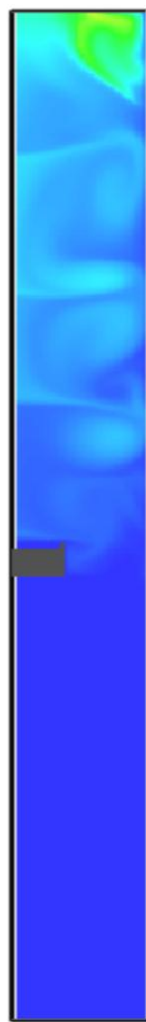

Slice Temp $\left({ }^{0} \mathrm{C}\right)$

1243

1121

998

876

754

631

509

387

265

142

20.0

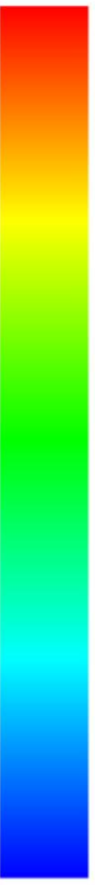

Figure 6: Slice temperature of cup-burner simulation at $t=0 s, 5 s, 10 s, 15 s, 16.5 s$ (flame extinction) and 20s

flame was extinct.

The effect of suppression for cases of $10 \mathrm{~L} / \mathrm{min}, 20 \mathrm{~L} / \mathrm{min}$ and $30 \mathrm{~L} / \mathrm{min}$ showed similar trends in temperature reduction and increase in nitrogen concentration. Table 4 shows a comparison between the extinguishing concentrations observed in CFD simulations, Ural's (2003) experiment [20] and the cup burner test performed for verification. The results show good agreement between the values obtained through simulations and experiments at $40 \mathrm{~L} / \mathrm{min}$ and $30 \mathrm{~L} / \mathrm{min}$ air flow. 


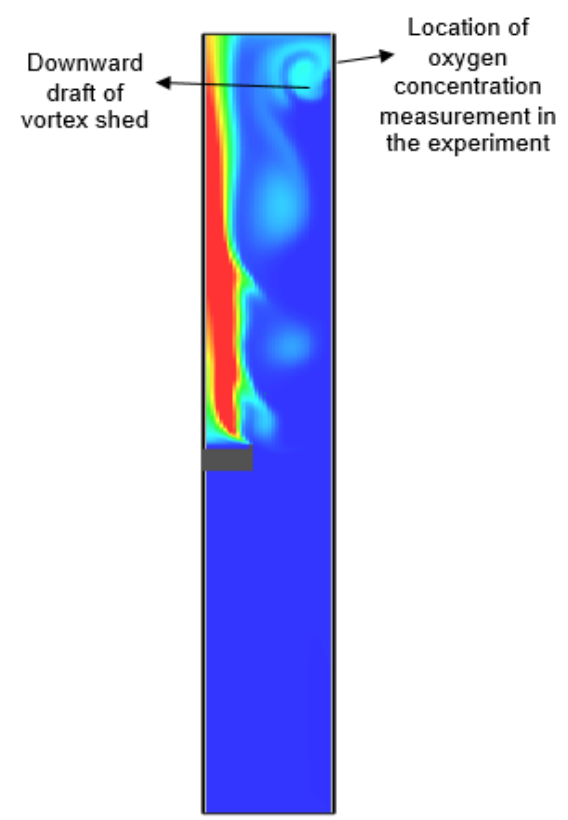

Figure 7: Case of $10 \mathrm{~L} / \mathrm{min}$ airflow showing vortex generation that affects measurement in experiment

The results obtained during the experiments were also in agreement with the investigation conducted by Ural which established higher agent concentrations for lower air flow rates to achieve fire suppression in both halocarbon and inert gas agents [20]. In the experiment, the extinguishing concentration was measured upstream of the cup-burner apparatus. However, CFD revealed that there are secondary downward draft flows from the exit plane. This downward draft flow caused by the vortex at the top of the chimney (See Figure 6) can result in erroneous test results. Due to the pulsating nature of the flow at low air flow rates (20 $\mathrm{L} / \mathrm{min}$ and $10 \mathrm{~L} / \mathrm{min}$ case), the experiment recorded lower extinguishing concentrations. However, in the CFD simulation, the extinguishing concentration does not vary significantly as the effect of the vortex does not cause this error in calculation of additional nitrogen required for flame extinction. When a sensor was included in the same location as that of the experiment, the CFD simulations also showed similar concentration at low air flow rate (around 13\% oxygen concentration) which gives an indication that measurement location plays an important factor in the estimation of design concentration in the cup-burner test in particular.

Table 4: Comparison between CFD, Ural's work and Cup-burner experiment

\begin{tabular}{|c|c|c|c|c|c|c|}
\hline \multirow{2}{*}{$\begin{array}{c}\text { Air } \\
\text { Flow } \\
\text { Rate } \\
\text { L/min }\end{array}$} & \multicolumn{3}{|c|}{$\begin{array}{c}\text { Additional Nitrogen Agent } \\
\text { Concentration }\end{array}$} & \multicolumn{3}{c|}{ Oxygen Concentration } \\
\cline { 2 - 7 } & CFD & $\begin{array}{c}\text { Ural } \\
(1999)\end{array}$ & Experimental & CFD & Ural (1999) & Experimental \\
\hline 40 & $33.6 \%$ & $32.7 \%$ & $33.9 \%$ & $13.9 \%$ & $14.1 \%$ & $13.8 \%$ \\
\hline 30 & $34.1 \%$ & $32.7 \%$ & N/A & $13.6 \%$ & $14.1 \%$ & N/A \\
\hline 20 & $33.9 \%$ & $35.6 \%$ & N/A & $13.9 \%$ & $13.5 \%$ & N/A \\
\hline
\end{tabular}




\begin{tabular}{|l|l|l|l|l|l|l|}
\hline 10 & $33.7 \%$ & $39.4 \%$ & $38.5 \%$ & $13.8 \%$ & $12.7 \%$ & $13.0 \%$ \\
\hline
\end{tabular}

The design concentration of nitrogen for flame extinction was determined to be $33.9 \%$ equating to an oxygen concentration of $13.8 \%$.

The weight of nitrogen used can be calculated using -

$$
W=\frac{V}{S} x\left(\frac{C}{100-C}\right)
$$

Equation 1

The calculated weight of nitrogen to be used to attain a concentration of $33.9 \%$ was $1.946 \mathrm{~g}$ in the experiment. The average weight of nitrogen used during the simulation (calculated in FDS) for the four different air flow rates was $1.938 \mathrm{~g}$. The error in the result is less than $1 \%$ thus validating the fire suppression modelled in FDS.

Table 5: Weight of nitrogen used in CFD simulation

\begin{tabular}{|c|c|c|c|}
\hline $\begin{array}{c}\text { Air flow rate } \\
\text { L/min }\end{array}$ & $\begin{array}{c}\text { Additional } \\
\text { Nitrogen } \\
\text { Concentration }\end{array}$ & $\begin{array}{c}\text { Suppression Time } \\
\text { (seconds) }\end{array}$ & $\begin{array}{c}\text { Amount of Nitrogen } \\
\text { used (grams) }\end{array}$ \\
\hline 40 & $33.6 \%$ & 16.2 & $1.93 \mathrm{~g}$ \\
\hline 30 & $34.1 \%$ & 16.8 & $2.03 \mathrm{~g}$ \\
\hline 20 & $36.4 \%$ & 16.0 & $1.90 \mathrm{~g}$ \\
\hline 10 & $38.1 \%$ & 15.8 & $1.89 \mathrm{~g}$ \\
\hline
\end{tabular}

\subsubsection{Pool fire simulation}

Figure 7 shows the temperature profile for the pool-fire case at a model depth of $1.25 \mathrm{~m}$. The fuel-air mixture combusted to generate a diffusion flame causing the temperature to rise in the chamber. Nitrogen injection commenced soon after the flame stabilised and the first thermocouple near the flame reached a value of $550^{\circ} \mathrm{C}$. The average ceiling temperature was approximately $140^{\circ} \mathrm{C}$ and the flame is stabilised at the start of the simulation. The nitrogen gas delivery was initiated automatically at approximately 3.5s. Upon introduction of nitrogen into the chamber, the average temperature started decreasing due to a fuel-rich condition as the oxygen concentration fell.

At time $=6$ seconds, the average ceiling temperature was $200^{\circ} \mathrm{C}$. At time $=12$ seconds, the nitrogen concentration started increasing gradually to a level where the fire was starved of oxygen to sustain combustion which can be seen in the figure.

At 18 seconds, the flame was subjected to instabilities due to reducing oxygen supply. The average ceiling temperature was approximately $185^{\circ} \mathrm{C}$. The contours showed local zones of re-ignition at the fire pool which temporarily combusts; however, it was unable to sustain combustion due to low oxygen concentration in the enclosure. The trend continued until the fire plume could not ignite the mixture anymore. 
At 25 seconds, there were no local zones of re-ignition and the fire suppression ceased when there was no indication of a flame and fire suppression was achieved. The measured additional nitrogen concentration at this point was $38.8 \%$ (volume). The corresponding oxygen concentration was $12.8 \%$.

At 30 seconds, the nitrogen is injected further post-fire suppression and the average ceiling temperature was $155^{\circ} \mathrm{C}$. However, the design concentration was measured at 24.6 seconds when there was no indication of flame.

Using equation 5 , the calculated weight of nitrogen required to reach a concentration of $38.8 \%$ was $9.906 \mathrm{~kg}$. The simulation reported that the additional nitrogen used was $9.84 \mathrm{~kg}$. The error in the calculation was less than $1 \%$ further validating the fire suppression model built using FDS.

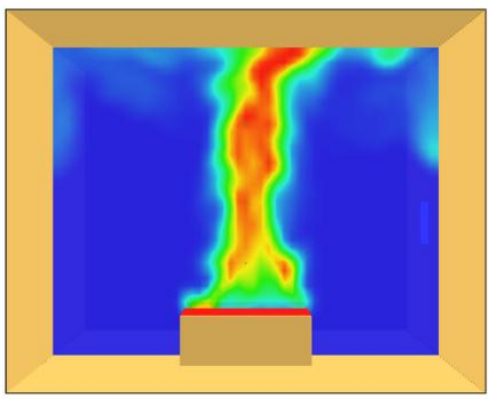

Os

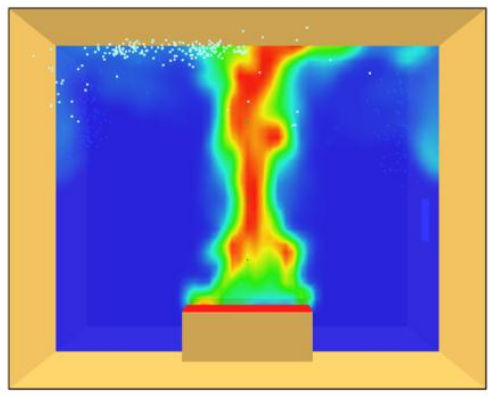

$6 s$

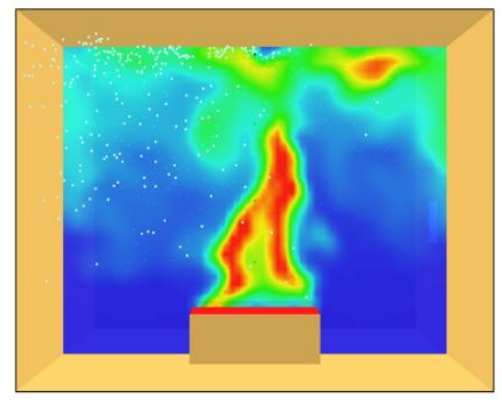

$12 \mathrm{~s}$

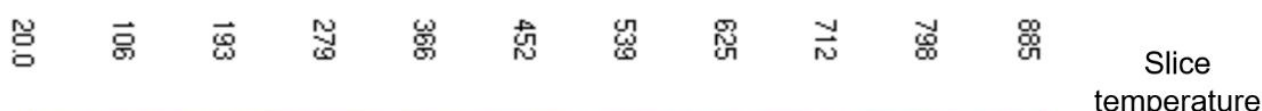

temperature

$\left({ }^{0} \mathrm{C}\right)$

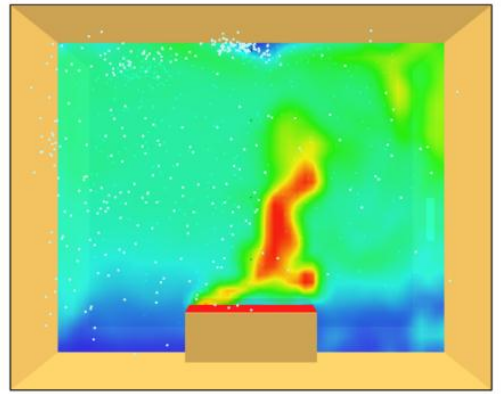

$18 s$

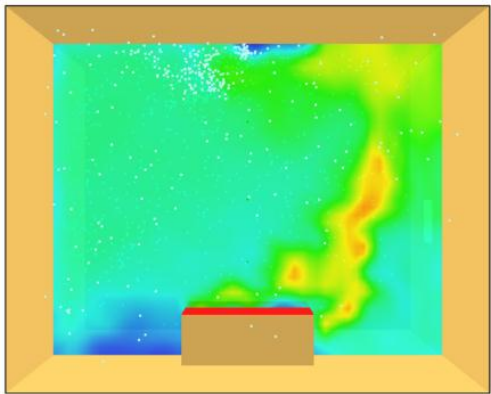

$25 s$

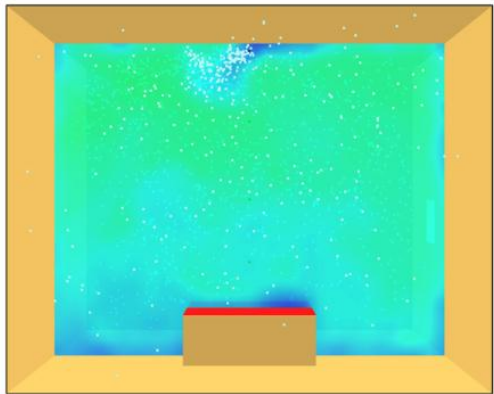

30 s

Figure 8: Slice temperature of pool-fire simulation at $t=0 s, 6 s, 12 s, 18 s, 25 s$ (fire suppression) and $30 s$

\section{Conclusions}

The ban on Halon production by an international agreement, led to a requirement to investigate alternative suppression agents that can be used on-board aircrafts for fire safety. This paper studied the performance of nitrogen in fire suppression and determined the required extinguishing concentration through modelling by CFD and BS ISO 14520 cup burner test. Nitrogen is relatively safe, is non-toxic and has good compliance for 
environmentally friendly applications. The novelty of this study is to evaluate the required oxygen concentration for fire suppression in a small-scale environment using CFD where an environmentally friendly agent - nitrogen is used.

The study revealed that the additional nitrogen agent extinguishing concentration for a propane-based cup-burner test is approximately $34 \%$ corresponding to an oxygen concentration of $14 \%$. CFD revealed that downward draft vortex causes erroneous measurement of concentration at relatively low air flow rates. The CFD model agreed with the results obtained through the experiment and Ural's work [20] regarding flame extinction in cup-burner tests. The SFPE [27] recommends a safety factor of 1.35 for minimum design concentrations for class $\mathrm{C}$ fires recorded during the cup-burner test. This results in a minimum design concentration of $46 \%$ for nitrogen to be used in practical applications.

Additionally, the fire suppression model was extended to a larger volume with n-heptane fire pool. The CFD study revealed that the extinguishing concentration for nitrogen was slightly higher; approximately $39 \%$ by volume corresponding to an oxygen concentration of $13 \%$ by volume. For fires in enclosures such as this one, Halon 1301 concentration required for fire suppression is approximately $5 \%$ by volume [10]. For the same enclosure volume $(2.5 \mathrm{~m} \mathrm{x}$ $2.5 \mathrm{~m} \times 2 \mathrm{~m}$ ), the weight of Halon 1301 required was $1.32 \mathrm{~kg}$. The weight of nitrogen required for the same procedure was 7.5 times more than that of Halon 1301. However, the replacement of Halon calls for use of new environmentally friendly agents like nitrogen which would be a suitable replacement for firefighting using fixed systems on-board aircrafts.

The influence of geometry, construction, combustible materials, total fire load and fuel load need to be carefully examined to understand the probability of fire risk in the cargo compartment [19]. This can greatly vary depending on the type of aircraft and needs to be assessed carefully to ensure that maximum safety levels can be assured. Nitrogen in excess can cause asphyxiation. This is an important factor when considering storage and handling and should be kept in mind as the amount of nitrogen stored in aircrafts will increase compared to the current Halon reserve on-board. Nitrogen would need to be stored under very high pressure (relative to Halon 1301) in order to reduce the number of the cylinders onboard and hence, to reduce the overall system weight. High pressure storage will require special certification for aircrafts and existing systems would need to be retrofitted to handle the higher discharge pressures. Currently, the maximum certifiable pressure at $15^{\circ} \mathrm{C}$ for fixed gaseous vessels on-board aircrafts is 344 bar [28]. The design of high-pressure nitrogen vessels should be kept in mind and explosion protection may be necessary when operating at such high pressures. It also an additional requirement that the fire suppression system should have maximum reliability in operation and discharge of the agent as it is a safety critical system for an aircraft. It is necessary to have redundancy or backup components like extra nitrogen cylinders, backup discharge and delivery piping for fixed fire suppression systems [29] (similar to Halon discharge systems).

\section{Future Work}

Further work prompted by the study described in this paper could lead to some interesting data on fire suppression. Considering the higher storage pressure for nitrogen, a high-speed CFD study would reveal more details about agent dispersion characteristics and how local agent concentrations influence fire suppression. This suppression model will be utilized to develop a full-scale cargo compartment model $\left(56 \mathrm{~m}^{3}\right)$ which will influence the design of the 
fixed fire suppression system in aircrafts that use nitrogen by studying the local agent/oxygen concentrations for different scenarios of MPS tests. Following this work, the four fire scenarios according to MPS [10] will be performed to evaluate and validate the performance of nitrogen agent for cargo fire suppression. These tests should help confirm design concentrations for large enclosures. The follow-on work will be made available in the upcoming publications. A minimum performance standard using Halon alternative agents may also be developed for aircraft engine bays as they are critical parts subject to fire risk in an aircraft. Further research and development of technologies should be based on the notion of a clean, green and sustainable future.

\section{Acknowledgement}

This work was supported and funded by Horizon 2020/ Clean Sky JU towards Grant Agreement No: 685482 "Environmentally-Friendly Fire Suppression System for Aircraft Cargo using Innovative Green Technology" (EFFICIENT) project. We would like to extend our sincerest acknowledgement towards the topic leader, AIRBUS, for providing us this opportunity and sharing relevant data towards this publication.

Author Statement

I would like to thank the reviewers for their consideration and valuable feedback that has helped improve the quality and relevance of the paper. A major change was introduced in the paper following the recommendation of the first reviewer. The cup-burner test was reconsidered and simulated in CFD in order to validate the fire suppression model results with the experiment. This fire suppression model was extended to a pool-fire case which further concretes the results obtained using the extinction and fire models incorporated in this study. Further to this, references from RESS journal were included as per the suggestion of the third reviewer. Some spelling mistakes and formatting were also rectified as pointed out by the second reviewer.

\section{Conflict of Interest}

The reviewer comments were addressed carefully and using engineering judgement. There are no conflicts of interest to be noted at this point of submission.

\section{References}

[1] BS ISO 14520 Annex B. Determination of flame-extinguishing concentration of gaseous extinguishants by the cup burner method. BS ISO 14520 -Part 1, "Gaseous fire-extinguishing systems - Physical properties and system design,” British Standards Institution. (2006)

[2] ASN Aircraft accident Sud Aviation SE-210 Caravelle VI-N VT-DWN BombaySantacruz Airport (BOM). Available at: https://aviationsafety.net/database/record.php?id=19761012-0 (Accessed: 30 June 2019). 
[3] Accident Description - South African Airways (1987) Aviation Safety Network.

Available at: https://aviationsafety.net/database/record.php?id=19871128-0 (Accessed: 12 July 2019).

[4] Tapscott, R, E; Speitel, L, C. (2002) Options to the Use of Halons for Aircraft Fire Suppression Systems-2012 Update. doi: DOT/FAA/AR-11/31.

[5] European Aviation Safety Agency (2011) 'Update of CSs in Order to Comply with EC Regulations'. Notice of Proposed Amendment (NPA) No 2011-14.

[6] "Security Considerations," 14 CFR Part 25, Section 795, U.S. Department of Transportation, Federal Aviation Administration.

[7] "Fire Extinguishers," 14 CFR Part 25, Section 851, U.S. Department of Transportation, Federal Aviation Administration.

[8] "Cargo Compartment Classification," 14 CFR Part 25, Section 857, U.S. Department of Transportation, Federal Aviation Administration.

[9] "Equipment, Systems, and Installations," 14 CFR Part 25, Section 1309, U.S. Department of Transportation, Federal Aviation Administration.

[10] Reinhardt, J.W., "Minimum Performance Standard for Aircraft Cargo Compartment Halon Replacement Fire Suppression Systems (2nd Update)," FAA report DOT/FAA/AR-TN05/20, June 2005, http://www.fire.tc.faa.gov/pdf/TN05-20.pdf (last visited $12 / 6 / 11$ )

[11] Margaret M. Hurwitz, Eric L. Fleming, Paul A. Newman, Feng Li, Eli Mlawer, Karen Cady- Pereira, Roshelle Bailey. (2015) 'Ozone Depletion by Hydrofluorocarbons', Geophysical Research Letters, 42(20). doi: 10.1002/2015GL065856.

[12] Stocker, T.F., D. Qin, G.-K. Plattner, M. Tignor, S.K. Allen, J. Boschung, A. Nauels, Y. Xia, V. B. and P. M. M. (eds). (2013) Climate Change 2013: The Physical Science Basis. Contribution of Working Group I to the Fifth Assessment Report of the Intergovernmental Panel on Climate Change. doi: 10.1017/CBO9781107415324.

[13] Brown, J.A., Jacobson, E., Dvorak, L.E., Gibson, J., Gupta, A., Metchis, K., Mossel, J.W., Simpson, T., Speitel, L.C., Tapscott, R.E., and Tetla, R.A. (1995) Chemical Options to Halons for Aircraft Use. International Halon Replacement Working Group, U.S. Department of Transportation, Federal Aviation Administration. doi: DOT/FAA/CT-95/9.

[14] Mcgrattan, K. and Mcdermott, R. (2016) 'Sixth Edition Fire Dynamics Simulator User's Guide'. doi: 10.6028/NIST.SP.1019

[15] McGrattan, K.; Hostikka, S.; Floyd, J.; Baum, H.; Rehm, R.; Mell, W.; McDermott, R. (2009) 'Fire Dynamics Simulator (Version 5) Technical Reference Guide, Volume 1: Mathematical Model', NIST Special Publication, 1018-5.

[16] Derrick, Alexander., Eric, L. (2010) 'CFD Modelling of Water Mist Fire Suppression', Defence R\&D Canada-Atlantic. 
[17] Adiga, K.C.; Hatcher, R.F. Junior; Sheinson, R.S.; Williams, F.W.; Ayers, S. (2006)

'CFD Modeling Options for Total Flooding Behavior of Ultra Fine Water Mist', Halon Options Technical Working Conference, May 16-18.

[18] G.E. Apostolakis et.al., (1995) 'Risk based spacecraft fire safety experiments', Reliability Engineering and System Safety 49. doi: https://doi.org/10.1016/09518320(95)00046-5

[19] Kostas J. Spyrou, Ioanna A. Koromila (2020) 'A risk model of passenger ship fire safety and its application', Reliability Engineering and System Safety, doi: https://doi.org/10.1016/j.ress.2020.106937

[20] Ural, E.A. (1999) 'Measurement of the Extinguishing Concentration of Gaseous Fuels Using the Cup-Burner Apparatus', in Halon Options Technical Working Conference, pp. 284-292.

[21] McGrattan, K.; Hostikka, S.; Floyd, J.; Baum, H.; Rehm, R.; Mell, W.; McDermott, R. (2009) 'Fire Dynamics Simulator (Version 5) Technical Guide, Volume 1: Mathematical Model', NIST Special Publication, 1018-5.

[22] Muller A, Jenft A, Collin A, Boulet P, Pianet G, B. A. (2014) 'Experimental and numerical study of pool fire suppression using water mist', Fire Safety Journal, 67, pp. 1-12.

[23] Yang, P., Liu, T and Qin, X. (2010) 'Experimental and numerical study on water mist suppression system on room fire', Building and Environment Safety Journal, 45(10), pp. 2309-2316.

[24] Kim S.C. and Ryou H.S. (2003) 'An experimental and numerical study on fire suppression using a water mist in an enclosure', Building and Environment Safety Journal, 38, pp. 1309-1316.

[25] Christopher L., Mathhew E.B., Daniel T.G., (2011) 'Fire dynamics and forensic analysis of liquid fuel fires' Report US Department of Justice, NCJRS, Grant No. 2008-DN-BX-K168.

[26] Wilcox, D. C. (1998) 'Turbulence Modeling for CFD', DCW Industries Inc., 2nd Edition.

[27] NFPA (2018) 'Standard on Halon 1301 Fire Extinguishing Systems', Standard 12A.

[28] "Harmonisation of the laws of the Member States relating to the making available on the market of pressure equipment" (2014). Journal of the European Union. Directive 201468/EU.

[29] U.S. Department of Transportation Federal Aviation Administration (2012) 'Fire Protection Systems', Aviation Maintenance Technician Handbook - Airframe, pp. 1-22. Available at: https://www.faa.gov/regulations_policies/handbooks_manuals/aircraft/amt_airframe_handbo ok/ 
[30] S.S.Arshi, M. Nematollahi and K. Sepanloo (2010) 'Coupling CFAST fire modeling and SAPHIRE probabilistic assessment software for internal fire safety evaluation of a typical TRIGA research reactor', Reliability Engineering and System Safety 95 (3). doi:https://doi.org/10.1016/j.ress.2009.09.006

[31] Z.Chen and J.P.Fielding (2018) 'A zonal safety analysis methodology for preliminary aircraft systems and structural design' Royal Aeronautical Society 58. doi:

10.1017/aer.2018.58 
2020-05-26

\title{
Performance evaluation of nitrogen for fire safety application in aircraft
}

\author{
Dinesh, Akhil
}

Elsevier

Dinesh A, Benson CM, Holborn PG, et al., (2020) Performance evaluation of nitrogen for fire safety application in aircraft. Reliability Engineering and System Safety, Volume 202, October 2020, Article number 107044

https://doi.org/10.1016/j.ress.2020.107044

Downloaded from Cranfield Library Services E-Repository 